\title{
America's Wellness Consumerism
}

\author{
Karina Sarandrea \\ College of Liberal Arts and Sciences
}

Faculty Mentor: Paul Ortiz, Department of History

\begin{abstract}
The purpose of the study is to investigate historical "wellness consumerism" and why it has continued to exist. Wellness consumerism is distinct from concepts like health consumerism in that it is not strictly related to or reinforced by the U.S. health care system. The opposite has tended to occur because of rampant online health misinformation. Present research does not unite public health, online health misinformation, and socioeconomic influences (e.g. the wellness movement and wellness economy) under a common framework nor does it examine them with a historical perspective. In addition, present research does not examine the relationship between online health misinformation and wellness trends. Medical journals, the history of the wellness movement, and oral history interviews from witnesses of the wellness movement were used to explore wellness consumerism's impact on people and public health. A study was conducted on a random sample of Amazon dietary supplements to investigate the relationship between health misinformation and affiliation with wellness trends. The results provide strong evidence for an association between the two, suggesting that producers of the wellness economy may be likely to spread health misinformation. Wellness consumerism resulted from co-optation of wellness by producers and has sustained longevity because it fills a gap in healthcare demand and worsens existing distrust in it. Wellness consumerism promotes a cycle of health information sharing that has negative implications for public health. This study highlights health problems uniquely associated with wellness consumerism and sheds light on other possible future socioeconomic challenges to public health while providing a basis for further consumer protections or health legislation that may be discussed in U.S. policy circles.
\end{abstract}

Keywords: wellness consumerism, wellness economy, wellness, public health, health misinformation, U.S. healthcare

\section{Introduction}

According to Anthony William, a "medical medium" supported by the likes of celebrities Gwyneth Paltrow and Pharrell Williams, celery juice heals people who suffer from chronic illness, acne, depression, and essentially every other existing ailment (Denett, 2019; William, 2021-a; William, 2021-b). Such claims are made without any scientific or medical accreditation and sold to consumers as a potential health solution despite them being largely unsupported by scientific research or basic medical knowledge (Denett, 2019). William is one pseudoscientific "expert" of many in an era of "superfoods", gluten-free everything, hydroFacials, and Fitbits. 
The promotion of health as a product has become a significant economic trend, encroaching into the health sector with food and dietary supplements increasingly indistinguishable from pharmaceuticals and "magic bullet" products sold as quick medicine solutions to bad health (Kickbusch and Payne, 2003, p. 276). There has been an "explosion" of wellness and health content online and in media because in this "highly unregulated health and wellness market" the distribution of knowledge is more profitable than the production of goods (Kickbusch and Payne, 2003, pp. 275-277).

The problem is that health information from non-professional sources places people at risk for negative health consequences (Seçkin, 2019). "Direct-to-consumer marketing by phony experts, celebrities with armies of Twitter followers, and legions of independent digital scammers (including some physicians)" without review or oversight has caused health misinformation to become pervasive (Armstrong and Naylor, 2019, p. E1).

The purpose of this research is to investigate whether wellness consumerism, or the interaction between wellness and health-seeking individuals with market forces, perpetuates health misinformation (a health-related claim of fact that is currently false due to a lack of scientific evidence) and why, generally, wellness consumerism continues to exist.

To explore the relationship between health misinformation and wellness consumerism, the effect of a product's affiliation with wellness trends on the presence of health misinformation in its description was examined using data collected from a sample of Amazon dietary supplements. Presence of health misinformation was measured dichotomously, present or not, by factchecking the health claims made in product descriptions with WebMd, a credible online health information resource. In addition, oral history interviews with two subjects, a pioneer of the well ness movement and a health consumer who witnessed its marketization, were conducted to understand the progression of wellness consumerism over time.

First, this paper will explain the types of consumerism in health and their connection to health information in a literature review. The review will cite previous studies, such as Ghenai et. al's modeling of health misinformation through the use of keywords, to provide context for how the research question will be evaluated.

Next, the theory section will use Marxist ideas of consumerism and commodification to define wellness consumerism and argue that it encourages the spread of health misinformation. The theory section will rationalize the use of interviews and both variables (affiliation with 
wellness trends and presence of health misinformation) to test this theory while outlining expectations for the study, namely that high affiliation with wellness trends increases the likelihood of health misinformation.

The rest of the paper is divided into how data was collected, an analysis of the results, and final conclusions. The monthly internet search volumes of wellness buzzwords in the titles of Amazon dietary supplements were used to determine their affiliation with popular wellness trends.

Logistical regression first produced insignificant results. However, after internet search volume data was adjusted to take larger popularity differences into account, regression produced statistically significant results. Interviews demonstrated that the wellness consumer movement is separate from the wellness movement and exists as a response to healthcare deficits, including those caused by social and economic inequality. The study is limited by a small sample size and imperfect data collection. More research is needed to evaluate the public health implications of wellness consumerism and unregulated online health information sharing.

\section{Literature Review}

While there seems to be a gap in research that investigates the health claims of wellnessassociated products or the development of wellness consumerism, this study draws from understandings of health consumerism and dynamics of health misinformation online, including social media, to develop a model for how and why popular wellness trends may drive the spread of false health information.

\section{Health Consumerism and Online Health Information}

Information pluralism encourages a consumerist orientation towards health (Seçkin, 2019). Health consumerism "refers to individual practices of the body, which are reinforced and supported by the healthcare system" (Merrild et. al, 2016). E-health information consumerism is the use of health information obtained from the Internet to manage personal health care (Seçkin, 2019).

Disatisfaction with medical care motivates individuals, especially women, to utilize the internet as their primary source of health information and to compensate for a lack of information received during medical encounters (Seçkin, 2019). While credible online sources of 
health information exist, the vast amount of available health information online encourages confirmation bias in information seekers (Swire-Thompson et. al, 2020).

\section{Spread of Health Misinformation on Social Media}

False medical information spreads faster than the truth on social media and has become an easy way to boost advertisements, ratings, and viewership (Swire-Thompson et. al, 2020; Kanekar et. al, 2019). A 2016 study on how information spreads via Twitter found that broadcasts, "where many people receive the information directly from the same source and the information becomes popular simply because influential accounts share it", were primarily responsible for the popularity of the information people consumed (Swire-Thompson et. al, 2020, p. 438).

In a study on twitter users that promoted "alternative" ineffective cancer treatments, users who spread health misinformation, or "rumor users" utilized a collection of keywords such as "juicing". The top word category dealt with eating and drinking. Juices, superfoods, and supplements were some of the most popular remedies found (Ghenai et. al, 2018).

\section{Previous Studies and Wellness Consumerism}

Health consumerism and e-health information consumerism imply a demand for health solutions and health information, which may in turn motivate the market to supply and broadcast its own unique, packagable versions of them to the public, resulting in what is now the wellness economy. This study will link both concepts to the structure of wellness consumerism.

Furthermore, as Ghenai et. al demonstrated, certain keywords are linked to health misinformation and popular wellness trends, such as the use of supplements to treat different ailments. Thus, this study will examine whether these words associated with wellness trends, or wellness buzzwords, will predict the likelihood, or presence, of health misinformation where increasingly popular buzzwords predict higher likelihoods of false medical information.

\section{Theory and Analysis}

According to Kenneth Arrow, Nobel Prize winner in economics and father of modern health economics, "where there is uncertainty, information or knowledge becomes a commodity" (Arrow, 1963, p. 946; Fuchs, 2017). Information, like other commodities, is "concentrated among those who can profit most from it" and, in the case of health information, "is being bought from most physicians" (Arrow, 1963, p. 946). 
While there has been a continuous demand for health information over time from patients seeking it from their doctors, there is additional, unmet demand, or uncertainty, from patients that lack access to healthcare or experience dissatisfaction with treatment. Consumerism is the seeking of "redress, restitution and remedy [by consumers] for dissatisfaction in acquiring the means to maintain their standard of living" (Mayer, 1981, p. 376). Wellness consumerism concerns the seeking of health information and health solutions (through the purchase of products and services) as a remedy for dissatisfaction in acquiring healthcare. Compared to other consumer movements, such as the consumer protection movement, the wellness consumer movement centers itself on access to health information, albeit incorrect, rather than corporate reform and takes from the wellness movement.

The wellness movement is associated with important health reform, and subsequently, better health outcomes. Affiliation with the wellness movement provides an air of legitimacy to those companies or individuals attempting to profit from supplying health information. This affiliation has transformed health consumerism into wellness consumerism, marketizing (integrating competition and price mechanisms into the once public service of healthcare, which included the distribution of health information) the wellness movement's emphasis on environmental health effects, diet, exercise, etc. while departing from the reinforcement or support of the U.S. healthcare system or official health organizations. This is what differentiates wellness consumerism from health consumerism.

Producers of the wellness industry thus have a financial incentive to spread health information because it provides them access to a host of health-minded consumers. They are further motivated to spread health misinformation because these falsehoods attract more attention and appeal to existing biases in the public. Disenchantment with the medical establishment makes consumers especially susceptible. 
The result is a self-reinforcing cycle that perpetuates the spread of online health misinformation (Figure 1).

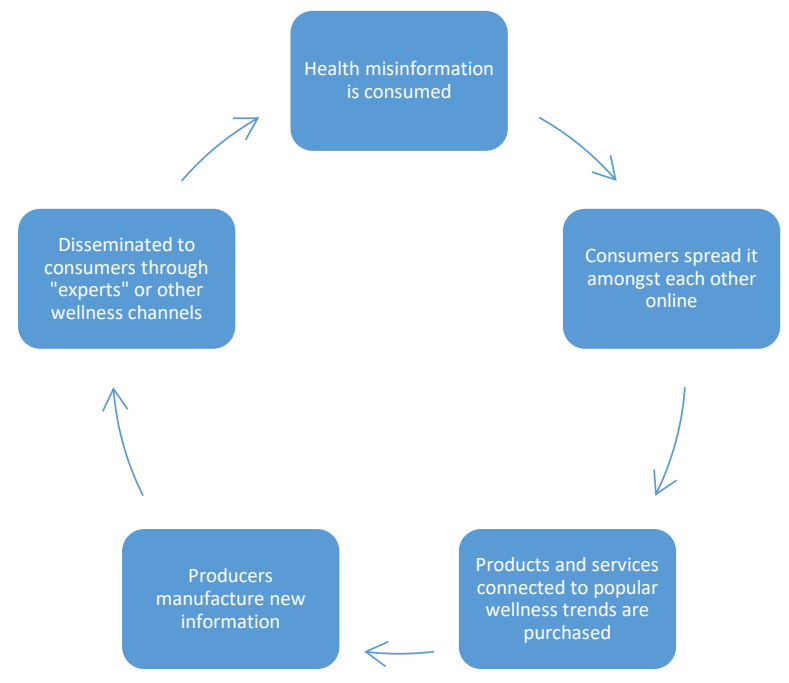

Figure 1. Health Misinformation-Wellness Trend Model.

People consume health misinformation, spread it amongst each other online, and act on itpurchasing products and services that reinforce it.

Consumer marketing contributes to the commodification process (Applbaum, 2000). Producers manufacture new health information that is false or backed by insufficient evidence to promote new products. This information is disseminated, or marketed, to consumers through wellness broadcasters, which includes "experts" (physicians, people claiming to be physicians, or any un-accredited individual that claims medical expertise) and other wellness marketing channels (blogs, websites, social media, etc.). Such efforts are driven by "the search for meaningful distinction" i.e. the need for marketers to differentiate themselves from their competitors (Applbaum, 2000, pp. 106-107). In addition to the regular advantages offered by producing health misinformation, competition is a powerful motivator. Wellness-affiliated companies must generate a flow of constant health information in order to market new products and engage their audiences, but scientific knowledge does not advance at their pace. In addition, even if new veritable knowledge were constantly available, companies could not all export the same information to market their products without losing competitiveness. Therefore, wellness consumerism perpetuates health misinformation by requiring its production in order to remain 
competitive-Arrow contends the market in healthcare fails - the market in health information fails too.

Moreover, once consumers purchase these products and buy into their claims, they are further alienated from the public health sphere, even if only from the effect of receiving "insider", "secret", or "new" information and solutions to problems the healthcare system did not or could not provide means to solve. Worse, the co-optation of science by products under wellness auspices through pseudoscience and use of "experts" further diminishes the consumer's trust in medical science and health professionals when these products do not return desired results. Combined, these effects in turn can cause consumers to seek wellness products and services in lieu of treatment, endangering public health.

To evaluate whether a relationship between health misinformation and wellness affiliation exists, I will record the presence of health misinformation in the product descriptions of Amazon dietary supplements and investigate whether it is associated with high affiliation to wellness trends.

Dietary supplements are a category of wellness products that have been used as remedies for a variety of symptoms and ailments, including cancer. Amazon, a company and one of the largest online retailers, sells many wellness products and offers over 13,200 different nutritional supplements to choose from.

Product propaganda is one way wellness industry producers can broadcast health misinformation to consumers. A product's affiliation with wellness trends should predict whether it contains any amount of health misinformation. Specifically, high affiliation should result in health misinformation. This is because companies react to the popularity of wellness trends, which can be based on false or unsubstantiated claims, by selling products that reinforce these claims in appeal to consumers. Companies may even be responsible for the popularity of these trends if they engaged in advertising that promoted misleading claims or false claims associated with them prior to launching their product directly or indirectly through the use of paid "experts".

Understanding the origin and composition of wellness consumerism also requires contemporary historical research, given it is a relatively new phenomenon. Thus, subjects who have lived through the wellness movement and witnessed the start of wellness consumerism will 
be interviewed to collect their oral histories. These will be subjects that can speak separately to the wellness movement and the shift away from public health spheres.

\section{Methodology}

For the first part of this study, data was collected from a random sample of Amazon dietary supplements. Systematic sampling was used to calculate a sampling interval of $k=N / n$ where $N$ $=13,200$ total dietary supplements (400 pages $\mathrm{x} 33$ products per page excluding repeated products [Figures 2 and 2.1]) $\mathrm{n}=30$ total dietary supplements sampled and $\mathrm{k}$ was randomly started at 440. Amazon was accessed on a private browser without logging in and navigated to the "All" section next to "Best Sellers", clicking "See All" under "Shop by Department", "Beauty \& Health", "Vitamins and Dietary Supplements" (Figure 2.2), and then "Supplements" (Figure 2.3).

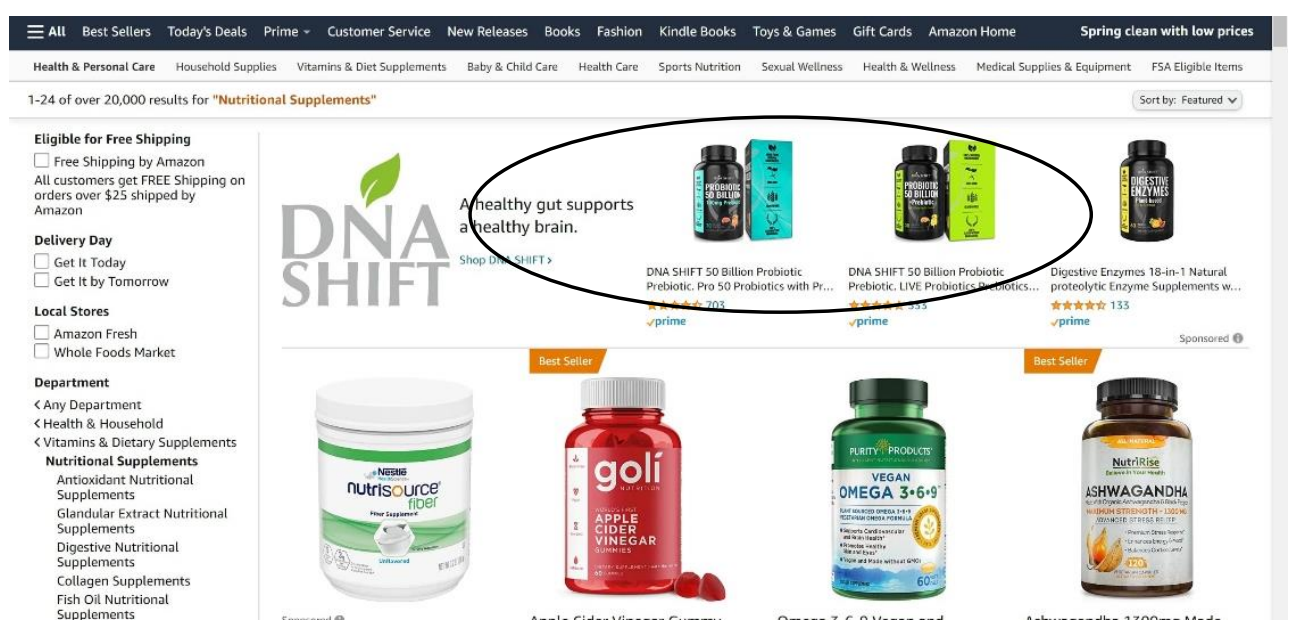

Figure 2. Excluding repeated products from sample. 


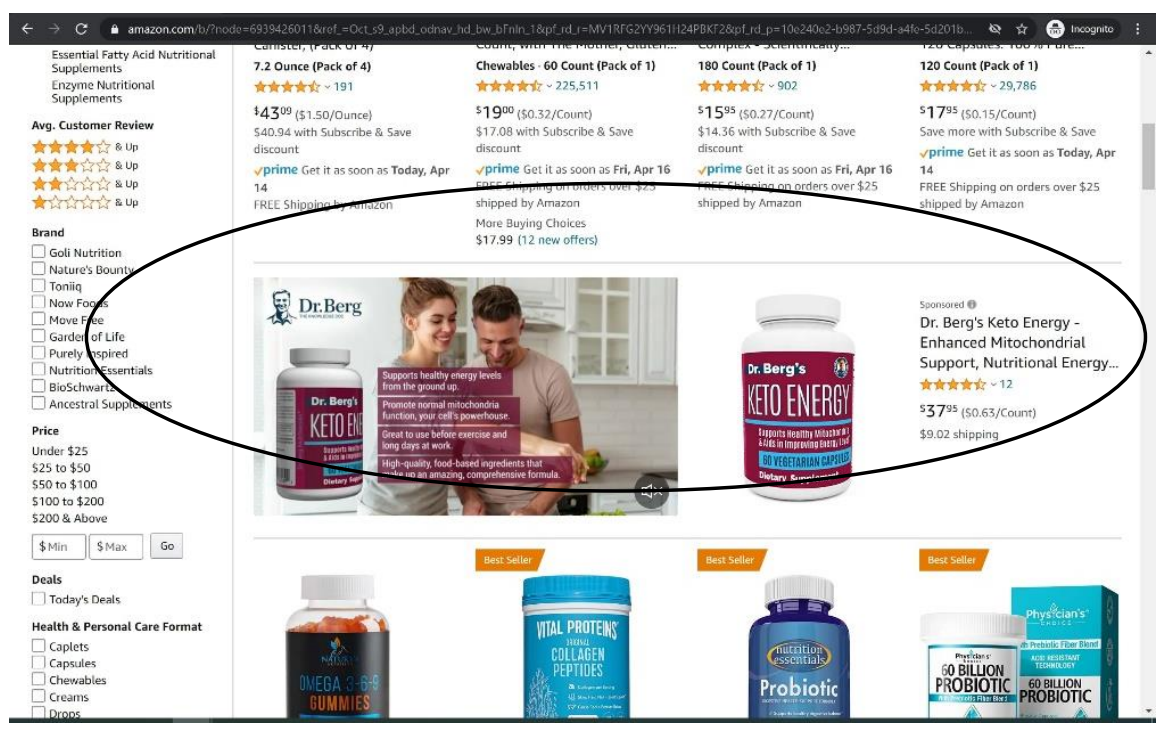

Figure 2.1. Excluding products with big advertisements from sample (product from advertisement could be targeted based on search history, and so not random).

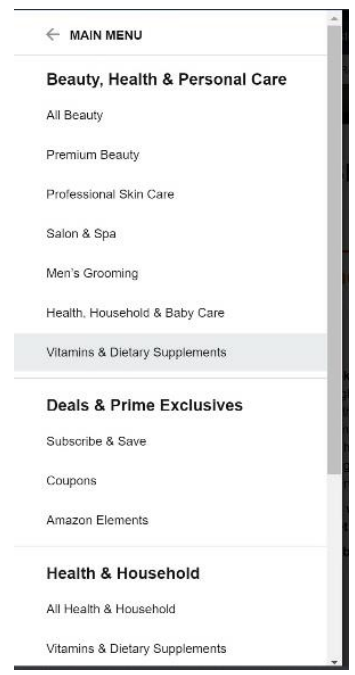

Figure 2.2. Navigating to Vitamins \& Dietary Supplements on Amazon.

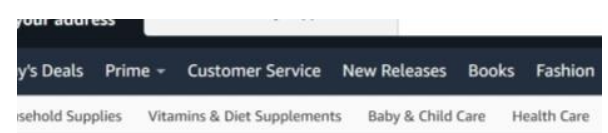

Vitamins \& Dietary Supplements

Featured categories

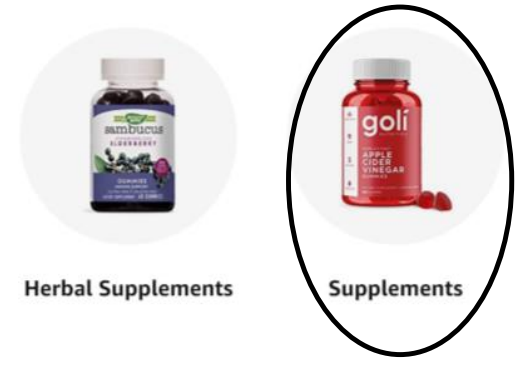

Figure 2.3. Navigating to Supplements on Amazon. 
The nth product was clicked on and information was collected from the product title and description for the study's variables. To operationalize the independent variable, affiliation with wellness trends, the study measured the popularity of wellness buzzwords, or keywords, found in product titles. The presence of wellness buzzwords indicates affiliation with wellness trends. High popularity of these words indicates high affiliation with popular wellness trends. The wellness buzzwords in a given title were noted (Figure 3), excluding words with ambiguous or more widely applicable meanings. Wellness buzzword was defined as "any word associated with wellness trends, including trending ingredients". The internet was consulted to become familiar with current wellness trends before this data was collected. The present study also relied on personal knowledge of the researcher. All words collected will be provided in a diagram with the results so other researchers may verify their affiliation with trends and reproduce the study.

A free Chrome Extension from Ubersuggest, a search engine optimization (SEO) tool, was used to measure the popularity of the buzzwords collected (Figures 3.1 and 3.2). It provided the search volume for a given word or phrase per month. It is expected that the popularity of the buzzwords is constant so while estimates given by different SEO tools may vary, Ubersuggest should catch the general trends of popularity. Search volumes were added together if there were multiple buzzwords for a cumulative wellness affiliation score.

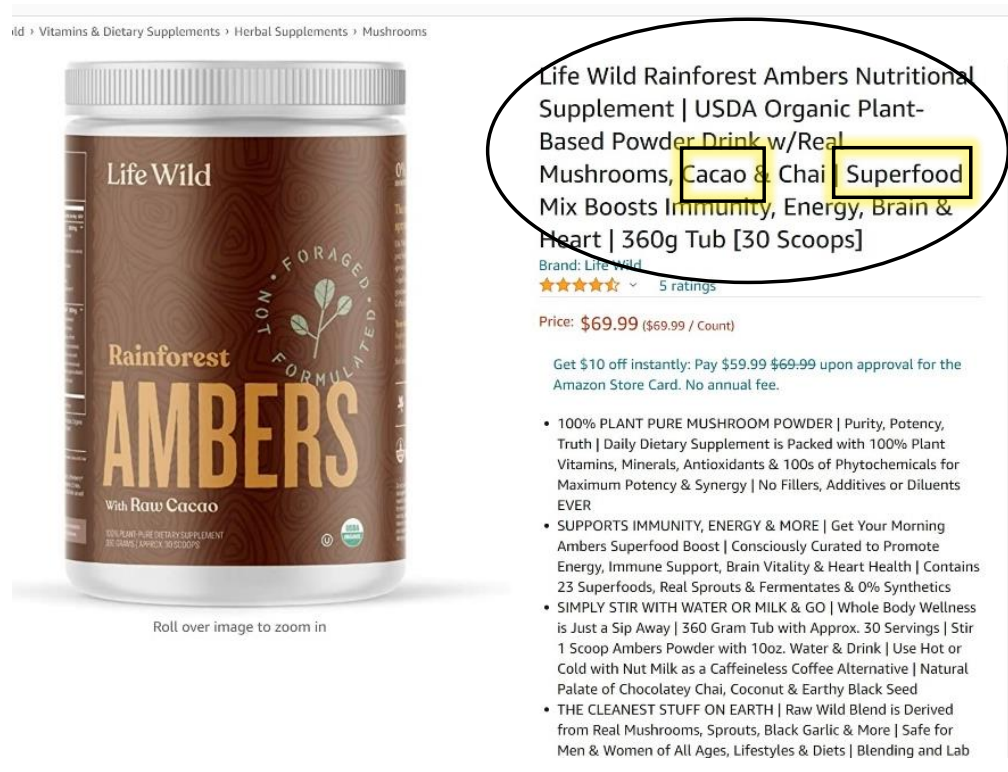

Figure 3. Noting wellness buzzwords in the title of an Amazon product. 


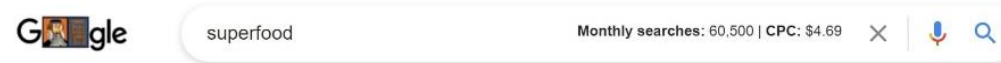

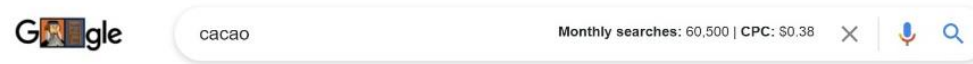

Figure 3.1. Typing in wellness buzzwords into Google using UberSuggest chrome extension.

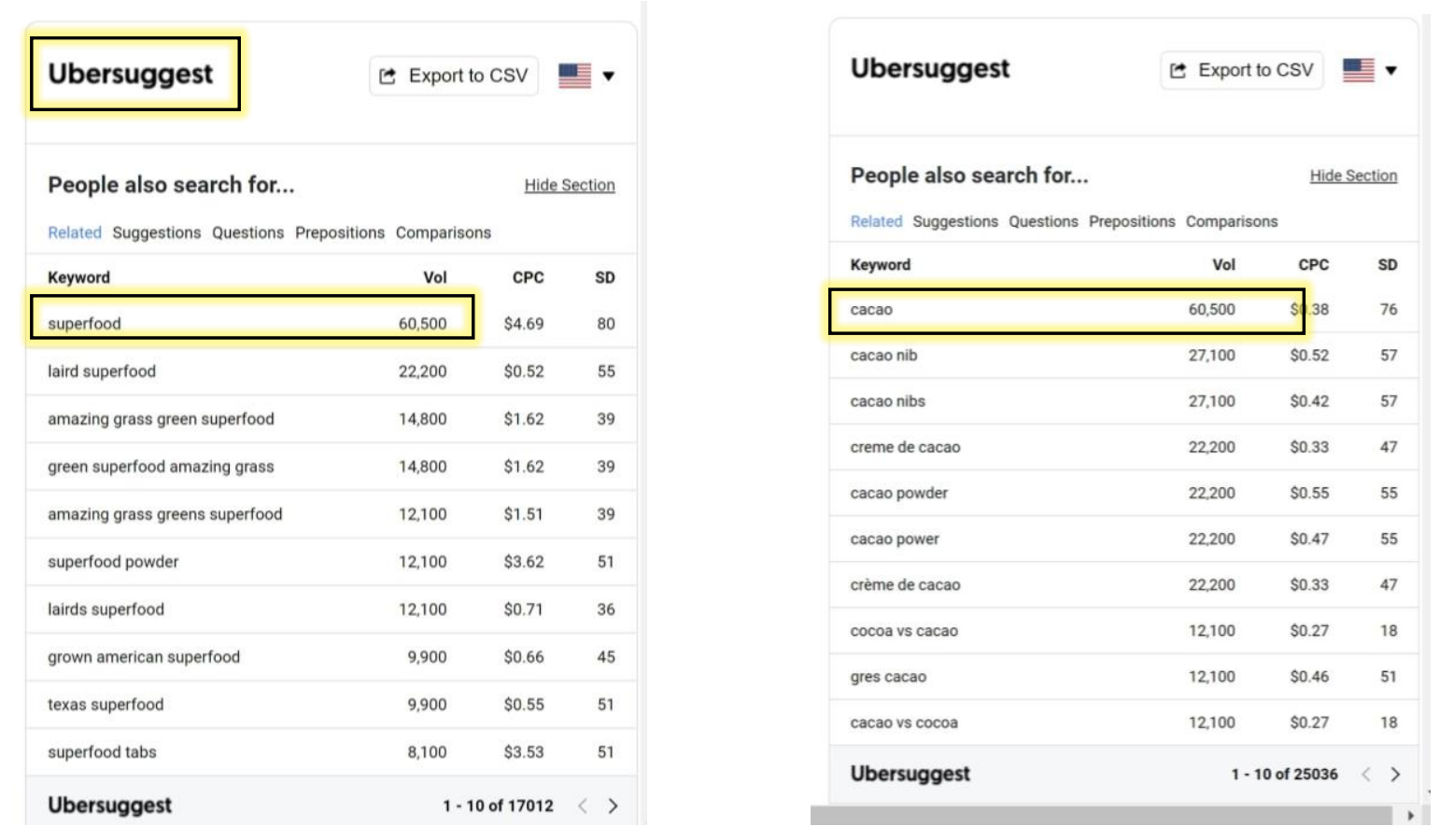

Figure 3.2. UberSuggest provides results for similar words.

To operationalize presence of health misinformation, the dependent variable, the present study reviewed the descriptions of each product sampled and used the WebMD Vitamin \& Supplement Center to fact-check their claims. Descriptions include text under the title of the product and the section titled "Product Description". If a health-related claim that was false or misleading due to a lack of scientific evidence was encountered, or health misinformation, the product was marked with 1 , to indicate the presence of health misinformation. Products with 
descriptions not found to contain health misinformation were marked with 0. WebMD was used to provide consistent claim checking (Figure 4). It is considered a generally reliable source of health information. The Vitamin \& Supplement Center provides a summary of the available scientific evidence pertaining to a certain ingredient or supplement. A detailed example of how health misinformation was collected can be found in the results section.

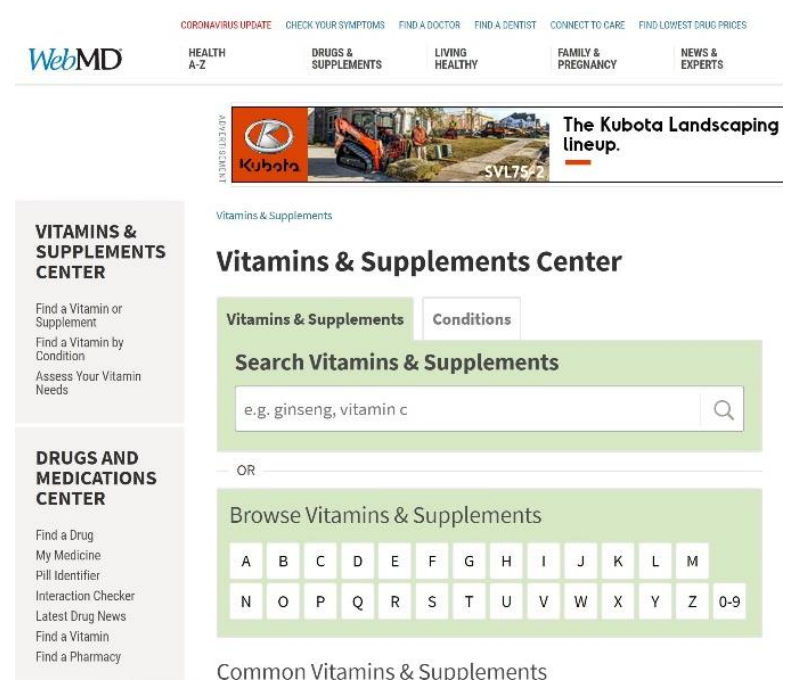

Figure 4. WebMD vitamin and supplement search tool.

Data from both variables was analyzed using binomial logistic regression. Results were calculated with R statistical programming on the R Studio IDE.

For the qualitative part of this study, the oral histories of two individuals were collected: Donald B. Ardell and a female subject who will remain anonymous. Donald B. Ardell was a pioneer of the wellness movement responsible for bringing it to health organizations and promoting it to the public (Figure 5). He was asked various questions about the start of the wellness movement and how he has witnessed it change, particularly in relation to healthcare. The second interviewee has been a consumer of the wellness economy since its start and has retreated from healthcare. She was asked questions about what influenced this decision and her trust in wellness, U.S. healthcare, and health professionals was gaged. Interviews were conducted via Zoom conferencing for approximately 45 minutes to 1 hour each. Interviews were recorded and transcribed. 


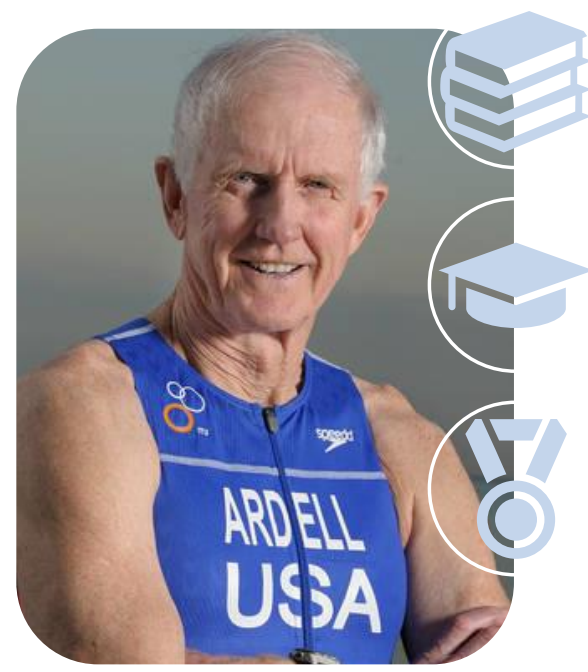

Ardell wrote various articles in the American Journal of Health Planning that described how health planning could be reoriented from regulating hospital expansions to promotoing healthy lifestyles.

He also wrote High Level Wellness: An Alternative to Doctors, Drugs, and Disease, which was published in 1976 and whose success helped spark the wellness movement.

Ardell holds a doctorate in health and public policy from Union University. He was an adjunct professor at the University of Central Florida where he guided their Campus Wellness Cener from 1984 unti 1996.

Ardell has been a member of the National Wellness Institute board of trustees for over a decade. He was awarded the Healthy America Fitness Leaders Award in 1991 by the President's Council on Physical Fitness and Sports.

Figure 5. Brief biography of Donald B. Ardell.

\section{Results and Interpretation}

Life Wild Rainforest Ambers Nutritional Supplement, a mushroom powder whose ingredients include shiitake mushrooms, claimed in its description that mushroom powder supports immunity and heart health (Figure 4.1) Typing in mushroom into the WebMD tool and clicking on shiitake (Figure 4.2) revealed there is no good scientific evidence to support the use of shiitake mushroom for boosting immune systems or "other conditions" (Figure 4.3). There is insufficient evidence for its use in improving hardening of the arteries or high cholesterol, two of the leading causes of heart disease (Figure 4.4). WebMD did not note any supporting evidence. The product was thus marked with a 1 to indicate the presence of health misinformation in its description. 


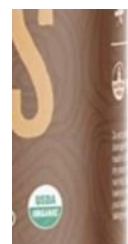

- 00\% PLANT PURE MUSHROOM POWDER Purity, Potency, ruth Daily Dietary Supplement is Packed with $100 \%$ Plant Vitamins, Minerals, Antioxidants \& 100s of Phytochemicals for Maximum Potency \& Synergy | No Fillers, Additives or Diluents EVER

- SUPPORTS IMMUNITY, ENERGY \& MORE Get Your Morning Ambers Superfood Boost | Consciously Curated to Promote Energy, Immune Support, Brain Vitality \& Heart Health | dontains 23 Superfoods, Real Sprouts \& Fermentates \& 0\% Synthetics

- SIMPLY STIR WITH WATER OR MILK \& GO | Whole Body Wellness is Just a Sip Away | 360 Gram Tub with Approx. 30 Servings | Stir 1 Scoop Ambers Powder with $10 \mathrm{oz}$. Water \& Drink | Use Hot or Cold with Nut Milk as a Caffeineless Coffee Alternative | Natural Palate of Chocolatey Chai, Coconut \& Earthy Black Seed

- THE CLEANEST STUFF ON EARTH | Raw Wild Blend is Derived from Real Mushrooms. Sprouts. Black Garlic \& More I Safe for

Figure 4.1. Product description for Life Rainforest Ambers Nutritional Supplement.

\begin{tabular}{l} 
Vitamins \& Supplements Conditions \\
Search Vitamins \& Supplements \\
\hline shiitake mushroom \\
\hline poria mushroom \\
maitake mushroom \\
coriolus mushroom \\
shiitake mushroom \\
reishi mushroom \\
C, agaricus mushroom
\end{tabular}

Figure 4.2. Typing mushroom and clicking on shiitake mushroom. 
were below 42,750 while $75 \%$ of search volumes were below 342,625 (Figure 6). The wellness buzzwords collected are modeled in Figure 6.1.

\begin{tabular}{|c|c|}
\hline \multicolumn{2}{|c|}{$\begin{array}{c}\text { Descriptive Summary of Dietary Supplement } \\
\text { Data }\end{array}$} \\
\hline Characteristic & $\mathbf{N}=30^{7}$ \\
\hline Wellness.Buzzword.Popularity & $135,775(42,750,342,625)$ \\
\hline Health.Misinformation.Presence & $18(60 \%)$ \\
\hline \multicolumn{2}{|l|}{${ }^{7}$ Median (IQR); n (\%) } \\
\hline \multicolumn{2}{|c|}{ Word popularity measured by monthly internet search volume } \\
\hline
\end{tabular}

Figure 6. Summary of collected data.

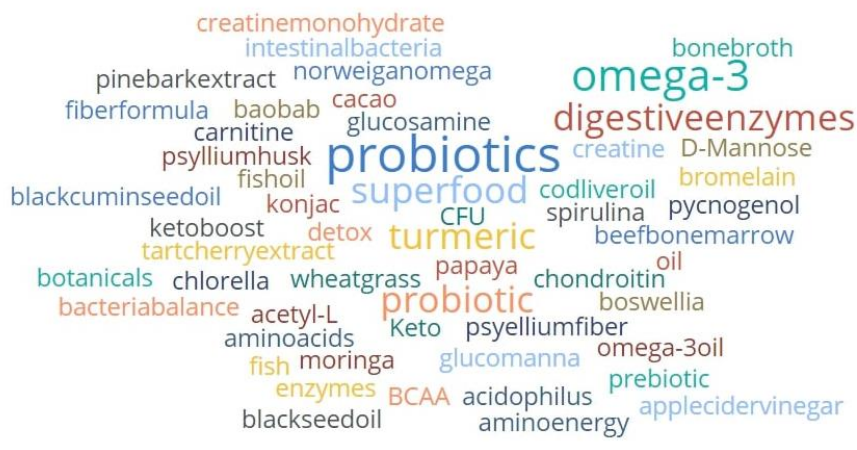

Figure 6.1 Trending ingredients and wellness buzzwords from the sample. The size of the word indicates its frequency in the sample (bigger words were in multiple product titles).

Initial results of the logistic regression displayed a significant $\mathrm{p}$-value, however, the large differences in search volumes (demonstrated by their interquartile ranges) conflicted with the data (Figure 6.2). This made sense given 1- or 2- digit differences in search volume are not particularly meaningful when comparing popularity. Search volumes needed to be adjusted to smaller values in order to evaluate their true effect on the presence of health misinformation. The 
search volumes collected were each divided by 10,000. An additional logistic regression revealed statistically significant results that are perhaps a bit weak (Figure 6.3). An odds ratio greater than one indicates health misinformation is more likely to be present in products highly affiliated with wellness trends. The $95 \%$ confidence interval does not include one, allowing for rejection of the null hypothesis. The p-value is also significant at $\alpha=.05$. There is an approximately $9 \%$ increase in the likelihood of health misinformation for every 10,000 unit increase in the popularity of wellness buzzwords. This equates to a 54\% likelihood of health misinformation in products with a 60,000 unit increase in popularity.

\begin{tabular}{|c|c|c|c|}
\hline \multirow[b]{2}{*}{ Characteristic } & \multicolumn{3}{|c|}{$\begin{array}{l}\text { Logistic regression for presence of health } \\
\text { misinformation in Amazon dietary } \\
\text { supplements }\end{array}$} \\
\hline & $\mathbf{O R}^{7}$ & $95 \% \mathrm{Cl}^{1}$ & p-value \\
\hline \multicolumn{3}{|c|}{$\begin{array}{l}\text { Figure 6.2. Logistic regression results with initial data. } \\
\text { Wellness.Buzzword.Popularity } 1.00\end{array}$} & 0.016 \\
\hline \multicolumn{4}{|c|}{$={ }^{1} \mathrm{OR}=$ Odds Ratio, $\mathrm{Cl}=$ Confidence Interval } \\
\hline & \multicolumn{3}{|c|}{$\begin{array}{c}\text { misinformation in Amazon dietary } \\
\text { supplements }\end{array}$} \\
\hline Characteristic & $\mathbf{O R}^{1}$ & $95 \% \mathrm{Cl}^{1}$ & p-value \\
\hline Wellness.Buzzword.Popularity & 1.09 & $1.03,1.18$ & 0.016 \\
\hline
\end{tabular}

Figure 6.3. Logistic regression results with search volume adjusted by 10,000.

\section{Interviews}

"The term wellness has been so broadly spread about that it can mean anything" says Donald B Ardell, full-time promoter of wellness. When he wrote one of the first books about wellness in 1977, wellness had specific meanings and they were much different than what they are now. Wellness was initially "a positive approach" to getting healthier and happier. It did not involve illness and "did not in any way" involve medical treatment, commercial services, or any products. Ardell recalls from his period of sharing the wellness philosophy (which he developed as his doctoral dissertation) at universities and businesses around the world, that people did not associate wellness with these things in the beginning. He considers the concept of wellness in 
recent times to be "misused" and emphasizes that "real" wellness is, among other tenets, based on respect for evidence and science and does not require a "guru". Ardell notes that hospitals and "various healthcare system players" can encourage people to do more for themselves, but class and social inequity does not allow everyone the opportunity.

A 64-year old Florida resident recalls her first negative experience with the medical system. After becoming pregnant in college at age 19, she sought to "have her tubes tied" but all the doctors she consulted refused to operate, citing her young age and gender. The subject recalls her preference for the operation even before becoming pregnant and working three jobs to support her son. A science and math major, a recent chemical lab explosion had given her liver damage, resulting in a month-long hospital stay during which her condition significantly worsened and she became diabetic.

When she eventually recovered, the subject was left with long-term liver-related health problems. She recalls doctors in the 1970s and early '80s said her liver would recover and insisted she "just needed to quick working so much". However, the subject struggled with chemical sensitivity, an environmental illness that caused her to sleep and work outside for twenty years, until she was able to move into a house with the proper conditions. Doctors simply "did not believe in it" and she gradually stopped raising it as a concern to them altogether. She then developed Celiac's Disease, but doctors again had difficulty “believing” her symptoms. The subject has used acupuncture and naturopathic medicine as alternative medical treatments. Recently, doctors have finally started to recommend her treatments but the subject no longer wishes to engage with the medical system the way she did before. Her trust in it, which was not high before, has plummeted.

The one positive experience with U.S. healthcare the subject remembers was with the treatment she was fortunate to receive from a highly regarded physician at Stanford University Medical Center. The subject fondly recalled the physician's attentiveness to her needs and acknowledgement of her pain.

\section{Conclusion}

Wellness consumerism perpetuates health misinformation through a cycle of health information sharing that legitimizes the purchase of certain products or services to treat or improve an individual's health by any degree, usually without the reinforcement or support of 
the U.S. healthcare system or official health organizations. Wellness consumerism came about from a market response to health consumerism and to the influential wellness movement that occurred alongside it. Because online health information is widely accessed and consumed, companies and individuals have taken to broadcasting it under the guise of wellness, regardless of whether they are qualified to or not. An analysis of the health-related claims made by 30 different Amazon dietary supplements found $60 \%$ contained health misinformation and that for every large (approximately 10,000 unit) increase in a product's affiliation with wellness trends, there was a $9 \%$ increase in the likelihood it contained health misinformation. This result provides support for a relationship between health misinformation and the wellness economy.

Interviews with subjects that could speak to the history of the wellness movement and the retreat from public health spheres revealed that wellness consumerism has sustained longevity by filling a gap in healthcare demand and worsening existing distrust in it. Deficits in the health system, such as a missing acknowledgment of environmental illness and gender and racial inequities are what create this gap. Quality healthcare does exist, but it is mostly only accessible to those with higher financial means.

The concept of wellness has been co-opted by producers who have falsely implied that it or it alone can be used to treat health issues and that wellness has negative requirements consumers must fulfill through the purchase of products and services. Wellness was not meant to compensate for inaccessible or insufficient healthcare, it was a philosophy originally intended to complement public health planning by the healthcare system and to empower individuals.

The wellness consumer movement raises concerns about the effect of health information commodification on public health and trust in the medical establishment. The market fails where promotion of false health information is more advantageous than that of the truth, ultimately placing consumers at risk.

There are many limitations to this study. The dichotomous nature of the dependent variable, presence of health misinformation, required a thorough analysis of Amazon product descriptions where a vague or hidden health-related claim of fact could have been missed or falsely interpreted as health misinformation. More time, scrutiny, and samples are needed to produce the best evaluation. Strict criteria involving a more credible source than WebMD, such as a team of accredited individuals or a medical fact-checking resource from an accredited health organization would provide more accurate assessments. Additionally, though selection of 
wellness buzzwords is a naturally more subjective process, drawing from a pre-determined word bank, possibly derived from relevant wellness market research would have eliminated the chance for personal bias to consciously or unconsciously influence the selection of buzzwords during data collection. The statistical results, though significant, are relatively weak suggesting the need for a greater sample size and for measurement of search volume, or popularity of wellness buzzwords, through more normally or favorably distributed data. This could be through a better SEO tool or keyword search volume information limited to that from a particular platform on social media.

Areas of future research could focus on evaluating the health claims in products other than dietary supplements and study whether consumption of these products is disproportionately by a certain class, gender, or ethnic group. More research is also needed on the constant development of the wellness movement, in or outside of the U.S., to evaluate its impact on public health and identify which aspects should be incorporated into health policy. The power of individuals like Anthony William to influence the health decisions of the American public should not be taken lightly. The rise of wellness consumerism has lead to a rise in health misinformation that must be addressed.

\section{References}

Applbaum, Kalman. (2000). Marketing and commoditization. Social Analysis: The International Journal of Anthropology, 44(2), 106-128. https://www.jstor.org/stable/23166536.

Armstrong, P. W., \& Naylor, C. D. (2019). Counteracting health misinformation: A role for medical journals? JAMA: The Journal of the American Medical Association, 321(19), 18631864. doi:10.1001/jama.2019.5168.

Arrow, Kenneth J. (1963). Uncertainty and the welfare economics of medical care. The American Economic Review, 53(5), 941-973. https://www.jstor.org/stable/1812044.

Denett, C. (2019, February 22). Celery juice will not work miracles, no matter what you read on Goop. Washington Post. Retrieved from https://www.washingtonpost.com/lifestyle/wellness/celeryjuice-will-not-work-miracles-no-matter-what-you-read-on-goop/2019/02/22/a4ddac18-348f11e9-af5b-b51b7ff322e9 story.html

Fuchs, V. (2017, March 8). Kenneth Arrow's legacy and the article that launched a thousand studies. Health Affairs. doi: 10.1377/hblog20170308.059100.

Ghenai, Amira, and Yelena Mejova. (2018). Fake cures: user-centric modeling of health misinformation in social media. Proceedings of the ACM on Human-Computer Interaction, 2(CSCW), 1-20. https://doi.org/10.1145/3274327. 
Kanekar, Amar Shireesh, and Avinash Thombre. (2019). Fake medical news: avoiding pitfalls and perils. Family Medicine and Community Health, 7(4): e000142. doi: 10.1136/fmch-2019-000142.

Kickbusch, I., \& Payne, L. (2003). Twenty-first century health promotion: the public health revolution meets the wellness revolution. Health Promotion International, 18(4), 275-278. https://doi.org/10.1093/heapro/dag418.

Mayer, Robert N. (1981). Consumerism in the '70s: the emergence of new issues. The Journal of Consumer Affairs, 15(2), 375-391. https://www.jstor.org/stable/23858976.

Merrild, C.H., Risør, M. B., Vedsted, P., \& Andersen, R. S. (2016). Class, social suffering, and health consumerism. Medical Anthropology, 35(6), 517-528. https://doi.org/10.1080/01459740.2015.1102248.

Seçkin, Gül. (2019). Expansion of Parson's sick role into cyberspace: patient information consumerism and subjective health in a representative sample of U.S. internet users. Social Science \& Medicine, 247(112733): 112733. https://doi.org/10.1016/j.socscimed.2019.112733.

Swire-Thompson, Briony, and David Lazer. (2020). Public health and online misinformation: Challenges and recommendations. Annual Review of Public Health, 41(1): 433-51. doi: 10.1146/annurevpublhealth-040119-094127.

William, Anthony. (2021-a). About Anthony William. Retrieved from https://www.medicalmedium.com/medical-medium-about-anthony-william

William, Anthony. (2021-b). Celery juice. Retrieved from https://www.medicalmedium.com/medicalmedium-about-anthony-william 